\title{
The Effectiveness of Specific Collagen Peptides on Osteoarthritis in Dogs-Impact on Metabolic Processes in Canine Chondrocytes
}

\author{
Michael Schunck $^{1 *}$, Helen Louton ${ }^{2}$, Steffen Oesser ${ }^{1}$ \\ ${ }^{1}$ Collagen Research Institute, Kiel, Germany \\ ${ }^{2}$ Department of Veterinary Sciences, Institute of Animal Welfare, Animal Behavior, Animal Hygiene and Animal Husbandry, \\ Faculty of Veterinary Medicine, Ludwig-Maximilian-University Munich, Munich, Germany \\ Email: *Michael.Schunck@cri-mail.de,h.louton@tierhyg.vetmed.uni-muenchen.de, Steffen.Oesser@cri-mail.org
}

How to cite this paper: Schunck, M., Louton, H. and Oesser, S. (2017) The Effectiveness of Specific Collagen Peptides on Osteoarthritis in Dogs-Impact on Metabolic Processes in Canine Chondrocytes. Open Journal of Animal Sciences, 7, 254-266. https://doi.org/10.4236/ojas.2017.73020

Received: May 4, 2017

Accepted: July 3, 2017

Published: July 6, 2017

Copyright $\odot 2017$ by authors and Scientific Research Publishing Inc. This work is licensed under the Creative Commons Attribution International License (CC BY 4.0).

http://creativecommons.org/licenses/by/4.0/

\begin{abstract}
In clinical trials over the past decade, the beneficial effect of orally administered collagen peptides in osteoarthritic dogs has been clearly demonstrated [1] [2] [3]. Although a statistically significant improvement in the lameness and vitality of dogs in general has been documented, the mode of action of the collagen peptide treatment is still under discussion. A previous study [3] indicated that the reduction in lameness and increased mobility in dogs after collagen peptide treatment were associated with a statistically significantly lowered plasma content of MMP-3, which is involved in collagen degradation. In addition, the content of the MMP-antagonist TIMP- 1 increased slightly after collagen peptide supplementation, suggesting a direct impact on the cartilage metabolism, particularly on the decrease of extracellular matrix degradation. Based on these findings, the impact of specific collagen peptides (PETAGILE $\left.E^{\circ}\right)$ on cartilage metabolism was tested in canine chondrocytes in the current investigation. In addition to the biosynthesis of various matrix molecules (type II collagen, aggrecan and elastin), the RNA profile of inflammatory cytokines and degenerative matrix molecules was investigated. The results showed clearly that the supplementation of specific collagen peptides reduced catabolic processes, as indicated by a statistically significant decrease in inflammatory cytokines and proteases in canine chondrocytes compared with untreated control experiments. In addition, a statistically significantly enhanced biosynthesis of type II collagen, elastin, and aggrecan was observed. Hence, the current data supports the suggested anti-inflammatory effect of specific collagen peptides, but also clearly demonstrates a pronounced stimulatory impact on matrix molecule synthesis. A combination of both observed effects might help to explain the previously reported clinical improvements after collagen peptide supplementation. Furthermore, the beneficial effect of
\end{abstract}


the specific collagen peptides was also confirmed in case reports on osteoarthritic dogs that demonstrated decreased lameness and increased vitality in the affected animals after PETAGILE treatment.

\section{Keywords}

Specific Collagen Peptides, Osteoarthritis, Dogs, Metabolism, Cartilage Tissue

\section{Introduction}

Osteoarthritis is a common degenerative joint disease in pets and humans. Dogs are mainly affected as a consequence of dysfunctions of the ankles and breeding-related ankle anomalies, as in German shepherd dogs [4]. Nowadays, dogs are used to a lesser extent as working animals like sheepdogs, hunting or guard dogs. Their role as an alternative life partner or pet dog leads to other urban-related alterations in these animals. An extended life span through optimized primary health care or, conversely, misconceived animal welfare with overfeeding or an inappropriate diet often leads to a degenerative osteoarthritic joint disease with symptoms of chronic pain and increasing lameness. Restricted vitality and disability is a direct consequence of the osteoarthritic defect in the dogs [5]. The American Pet Products Association (2011-2012 National Pet Owners Survey) estimated a canine population of 72 million dogs in the United States. Some 14 million of these dogs are estimated to be affected by osteoarthritis. Consequently, approximately $20 \%$ of dogs older than 1 year are suffering from osteoarthritis [6] [7], which also implies a reduction in the quality of life for the dogs' owners.

An improvement in animals' health conditions is, therefore, of widespread interest for pet owners. Current treatments tend to focus on osteoarthritic symptoms that alleviate inflammation and reduce pain by the use of Non-Steroidal Anti-Inflammatory Drugs (NSAIDS), but pay no attention to the actual cause [8]. In recent years, various so-called chondroprotective drugs for dogs and humans have appeared on the market. These nutraceuticals claim to provide a cartilage-protecting quality and anti-inflammatory characteristics. Although the efficacy of the chondroprotectives is still under discussion, they are promoted as safe and effective components for managing canine osteoarthritis without appreciable side-effects [6] [9] [10] [11] [12] [13].

A further supposed therapeutic approach for the treatment of osteoarthritis is the restoration of cartilage tissue by the injection of mesenchymal stem cells into the osteoarthritic affected joint. The idea behind this therapy is to enhance the cell count in the cartilage tissue and so stimulate the regeneration of extra cellular cartilage matrix. To date, these methods have failed to demonstrate the restoration of a durable cartilage surface to an osteoarthritic joint [14] [15].

Nevertheless, stimulation of the extracellular matrix synthesis seems to be a promising approach as it addresses not only disease-related symptoms, but focuses on the basic cause of osteoarthritis-the metabolic imbalance of the carti- 
lage.

Findings with an imaging method by McAlindon et al. in 2011 indicated for the first time that orally administered collagen peptides have the potential to stimulate proteoglycan synthesis in the knee joints of people with mild forms of osteoarthritis [16]. With this in mind, the aim of the current research was to investigate the effectiveness of specific collagen peptides on the metabolism of cartilage connective tissue in canine chondrocytes. Furthermore, the pre-clinical findings with specific collagen peptides were to be investigated under in vivo conditions in a small number of dogs with mild to moderate osteoarthritis. The investigation might help to introduce a new approach for the treatment of osteoarthritis in dogs and establish specific collagen peptides as an effective and safe chondroprotective agent. This could, in turn, improve the quality of life for millions of affected dogs.

\section{Materials and Methods}

\subsection{Study Design}

\subsubsection{In Vitro Examination}

The mechanism of action of specific collagen peptides for the gene expression profile and biosynthesis of extracellular matrix molecules was to be investigated in cell culture experiments on primary canine chondrocytes.

The canine chondrocytes (095Cn402-05, tebu-bio GmbH, Offenbach, Germany) were seeded on 12-well culture plates. The cells were kept in monolayer at $37^{\circ} \mathrm{C}, 5 \% \mathrm{CO}_{2}$ and $\mathrm{O}_{2}$-reduced atmosphere (5\%) and cultivated in Ham's $\mathrm{F} 12$ medium, supplemented with $10 \%$ fetal calf serum, $20 \mathrm{U} / \mathrm{ml}$ penicillin-streptomycin and $50 \mu \mathrm{g} / \mathrm{ml}$ ascorbic acid. The medium was renewed every second day until a cell confluence of $80 \%$ was reached. The regular medium was then replaced with the stimulation medium supplemented with $0.5 \mathrm{mg} / \mathrm{ml}$ of the specific collagen peptides.

For the gene expression studies, the chondrocyte monolayer cultures were treated for 24 hours in comparison with untreated control experiments. RNA was purified by extraction with the phenol (PeqGoldTriFast, VWR, Erlangen, Germany)-chloroform method. The RNA expression of matrix molecules and other chondrocyte related genes was determined semi-quantitatively via Realtime Polymerase-Chain-Reaction. The RT-PCR examination was performed (DyNAmo Flash SYBR Green, Thermo Scientific, MA, USA) after the RNA concentration had been photometrically determined. For each reaction, 10 to 40 ng of transcribed cDNA was added after individual optimization in preliminary tests for all genes. $12.5 \mu \mathrm{l}$ distilled water, 5.0 $\mu$ DyNAmo Flash Master Mix, and $1.25 \mu \mathrm{l}$ of the designed primer pairs described in Table 1 were used for the sample. The following reaction profile was programmed: Singular $7^{\prime} 95^{\circ} \mathrm{C}, 35-45$ repeated cycles of denaturation for $10^{\prime \prime}$ at $95^{\circ} \mathrm{C}$ followed by $15^{\prime \prime}$ at annealing temperatures (view Table 1) and elongation $20^{\prime \prime}$ at $72^{\circ} \mathrm{C}$. The reaction was stopped by a melting temperature of $60^{\circ} \mathrm{C}$ for $60^{\prime \prime}$. The RNA expression was determined in relation to the housekeeping gene GAPDH. For all the genes under 
Table 1. Primer sequences used for RT-PCR analysis.

\begin{tabular}{ccccc}
\hline Gene & Fwd. Seq $\left(5^{\prime}-3^{\prime}\right)$ & Rv. Seq $\left(3^{\prime}-5^{\prime}\right)$ & $\mathrm{T}_{\mathrm{m}}\left({ }^{\circ} \mathrm{C}\right)$ & Accession \\
\hline GAPDH & GTGACACCCACTCTTCCACC & GAGGCCATGTAGACCATGAGG & 55.0 & NM_001003142.1 \\
Collagen type II & TGGCTTCAAAGGCGAACAAG & TTTGGACCTGCCAGACCATC & 51.7 & XM_847773.3 \\
Aggrecan & CACTCAGGAGAGGAGACCCA & GCAGGTGGCTCCATTCAAAC & 55.0 & NM_001113455.1 \\
Elastin & GGCCTGGGAATTGGTGGTAA & CTCTTCCGGCCACAGGATTT & 53.2 & XM_005620958 \\
TNF $\alpha$ & GGCCTCCAACTAATCAGCCC & CTGGCTTGTCACTTGGGGTT & 55.0 & XM_001003244.4 \\
IL-1 $\beta$ & CAGCCAGTCTTCACTATTCAGGT & AGACTTGCAACTGGATGCCC & 50.0 & XM_005630074.1 \\
IL-6 & ACCACTCACCTCTGCAAACAA & GTGCCTCTTTGCTGTCTTCAC & 55.5 & NM_001003301.1 \\
MMP-13 & ACAACCACCAAGATGCTCCC & CCAGCAGGATTCAGGGGATAG & 61.8 & XM_536598.3 \\
ADAMTS4 & CATGTGCAACGTCAAGGCTC & CGACTCAGTGAAGCAAAGCG & 50.0 & XM_545768.4 \\
ADAMTS5 & TGTGGGAAGGGGAGGATCTG & GCGACCATTGTTTCTGGGTG & 64.6 & XM_846025.3 \\
\hline
\end{tabular}

investigation, the annealing temperature $\left(\operatorname{Tm}{ }^{\circ} \mathrm{C}\right)$ was optimized in a twelve-step gradient PCR amplification ranging from $50^{\circ} \mathrm{C}$ to $70^{\circ} \mathrm{C}$. PCR products were electrophoretically separated on a $2 \%$ agarose gel $(3 \mathrm{~g}$ agarose diluted in $150 \mathrm{~mL}$ buffer of $0.05 \mathrm{M}$ EDTA, $40 \mathrm{mM}$ Tris, $57.1 \mathrm{~mL}$ acetic acid) stained with $10 \mu \mathrm{L}$ GelRed (41003, BIOTREND Chemikalien GmbH, Cologne, Germany). Amplificated PCR products were analyzed in an Alpha Innotech Fluorchem Imager (Bio-Rad Laboratories GmbH, Munich, Germany). The PCR products were specified by a 50 bp-DNA-Fluoro-Ladder (8263.1, Carl Roth GmbH, Karlsruhe, Germany).

In the case of the biosynthesis of the main extracellular matrix molecules, commercial assay kits were used. For the collagen type II metabolism investigations, the amount of newly generated collagen was determined after three weeks of stimulation. Synthesized collagen was isolated by the Sircol assay (tebu-bio, Offenbach, Germany) in accordance with the manufacturer's instructions. In brief, the culture medium was discarded and adherent cell layers were digested in $0.1 \mathrm{mg}$ pepsin solution in $0.5 \mathrm{M}$ acetic acid at $4^{\circ} \mathrm{C}$ overnight. Cell suspensions were neutralized by the addition of $100 \mu \mathrm{l}$ acid neutral reagent, and synthesized collagen was subsequently separated by the supplementation of $200 \mu$ isolation \& concentration kit solution and vigorous agitation at $4^{\circ} \mathrm{C}$ overnight. After centrifugation (12,000 rpm, 10') and discarding of the supernatants, isolated collagen was re-suspended in $1 \mathrm{ml}$ Sircol dye reagent. After $30 \mathrm{~min}$ of agitation and further centrifugation, the collagen pellet was overloaded with $750 \mu$ l of cold acid-solid wash reagent. After centrifugation, the supernatant was again discarded and the enriched collagen was resolved in $250 \mu \mathrm{l}$ of alkali solution. $200 \mu \mathrm{l}$ of these sample solutions were taken for photometrical quantification of the synthesized collagen. The extinction was measured at $492 \mathrm{~nm}$. The amount was determined on the basis of standard measured collagen solutions.

The Blyscan glycosaminoglycan assay (tebu-bio, Offenbach, Germany) was used for the detection of aggrecan. The biosynthesis of proteoglycans was determined after a two-week stimulation. In accordance with the manufacturer's instructions, the cell layers were overloaded with $1 \mathrm{ml}$ papain extraction solution 
after the cell culture medium was discarded and incubated for $3 \mathrm{~h}$ at $65^{\circ} \mathrm{C}$ with vigorous agitation. The cell suspensions were centrifuged $\left(10,000 \mathrm{~g}, 10^{\prime}\right)$ and the supernatants were collected. After the addition of $1 \mathrm{ml}$ Blyscan dye solution and agitation $\left(30^{\prime}\right)$, the supernatants were again centrifuged $\left(12,000 \mathrm{rpm}, 10^{\prime}\right)$ and discarded. Isolated proteoglycan pellets were re-suspended in $500 \mu$ dissociation solution. $200 \mu \mathrm{l}$ per sample was determined photometrically at $656 \mathrm{~nm}$ in comparison to untreated control experiments.

The synthesis of elastin was determined by the Fastin elastin assay kit (tebu-bio, Offenbach, Germany). Chondrocytes were stimulated for 2 weeks with the specific collagen peptides or left untreated as a control experiment. After discarding the culture medium, the cell monolayers were solubilized with $250 \mu \mathrm{l}$ trypsin. Trypsin solution was removed after centrifugation $\left(3000 \mathrm{rpm}, 10^{\prime}\right)$. Cell pellets were resolved in $100 \mu \mathrm{l}$ oxalate acid solution $(1 \mathrm{M})$ and boiled for $1 \mathrm{~h}$ in a water bath. After cooling, $300 \mu \mathrm{l}$ elastin precipitation solvent was added to precipitate dissolved elastin within 15 minutes. After centrifugation (10'), the supernatant was discarded and the elastin pellet was resolved in $1 \mathrm{ml}$ dye solution by 90 minutes' agitation. After a repeated centrifugation and discarding of the supernatant the elastin pellet was re-suspended in $260 \mu \mathrm{l}$ dye dissociation solution. $200 \mu \mathrm{l}$ of the resolvents were used for photometrical elastin measurement at a wave length of $492 \mathrm{~nm}$.

\subsubsection{In Vivo Examination}

The pre-clinical findings on primary canine chondrocytes were validated on a small number of selected osteoarthritic dogs $(n=22)$. In these case reports, the efficacy of the specific collagen peptides was evaluated under in vivo conditions.

All the dogs in our current research had a treatment-resistant history. All previously performed treatment options had failed. The observational treatments conducted on these animals in our investigation were performed in accordance with guidelines for the care and use of laboratory animals [17] as well as the nutritional assessment guidelines for dogs and cats [18], and with the full consent of the pet owners.

An opportunity to use blood samples arose in three of the case subjects. These blood samples remained after routine blood tests in the veterinary practices and could be analyzed for potential biomarkers of cartilage metabolism. Commercial canine-specific ELISA kits were used for the cartilage biomarker analysis: In plasma samples, ELISA's for procollagen type II (CP II, 60-1003-001) and aggrecan chondroitin sulfate (CS846, 60-1004) from Ibex Pharmaceuticals, Montreal, Canada, and for the detection of hyaluronic acid (HA, MBS737480), cartilage oligomeric matrix protein (COMP, MBS012790), matrix metalloprotease-3 (MMP-3, MBS703093), and tissue inhibitor of metalloproteases-1 (TIMP-1, MBS006398), ELISA's were provided by My Biosource, Eching, Germany. All investigations were performed according to the manufacturers' instructions.

The specific collagen peptides used in the current research are commercially available under the brand name PETAGILE', provided by GELITA AG (Eberbach, Germany). The test product is composed of different specific collagen pep- 
tides with a high safety profile derived from a complex multistep procedure by the degradation of porcine type I collagen. It is classified as a safe food by the European Food Safety Authority (EFSA, 2005) and by the Food and Drug Administration (FDA, 2003).

The dogs received $5 \mathrm{~g}$ of the specific collagen peptides with their regular pet food once a day for a period of 12 weeks. Their usual veterinarians accompanied the course of treatment and provided information on the medical history of the animals by means of an orthopedic examination. The degree of osteoarthritis was assigned a lameness score on a 5-point scale from $0=$ no lameness to $4=$ high degree of lameness with relieving posture of the affected limb (Table 2). Lameness-related parameters, "pain at activity", "joint swelling", "instability" and "restriction of mobility" were evaluated on a 4-point scale from $0=$ without symptoms, 1 = low, 2 = moderate and 3 = severe symptoms. The validation of "pain at activity" was based on the characterization of step-wise abnormal behavior of the dogs in the palpation inspection. A low degree of pain at activity was characterized by licking flews, twitching the ears, looking in the direction of pain, and increased panting. A moderate degree was defined by anxiousness, loud panting, straining in the muscles of the OA affected limb, turning around to the painful ankle, and limping. A severe degree of pain at activity was determined if the dog was trembling and the whole skeletal musculature was strained. Also if the dog barked, whimpered, growled, or snapped.

Joint swelling was characterized by an increased amount of synovia fluid, which led to a graduated extension of the ankle volume.

Instability of the affected ankles was classified by the so-called drawer test.

Finally, with regard to the restriction of mobility, the maximum deflection possibility of the affected ankles was determined. The instability of the ankles and movement restriction was graded according to the expertise of the attending veterinarians.

The pet owners were asked to evaluate changes in the dogs' behavior regarding their everyday routine, such as "discomfort when climbing stairs" or "problems when standing up", and of their "vitality" in general. These parameters were evaluated on a 6-point scale with $1=$ near complete immobilization (90\%) to $6=$ no pain or restriction in mobility. In addition, "tenderness on palpation", which often occurs when combing, for example, is common in dogs suffering from backbone pain. Changes in this pain were evaluated in 3-categories because of the smooth transition between the degree of pain levels. It was classified as $1=$

Table 2. Degree of lameness.

\begin{tabular}{cc}
\hline Score & Description \\
\hline 0 & No lameness \\
1 & Indistinct, mild symptoms (only at trot) \\
2 & Deranged, consistent wearing (at step \& trot) \\
3 & Moderate degree, inconsistent wearing (only tiptoeing) \\
4 & High degree of lameness with relieving posture of the affected limb \\
\hline
\end{tabular}


no pain on palpation, $2=$ moderate contact pain, and $3=$ severe contact pain with defensive reactions (biting, snapping).

\section{Statistical Analysis}

Statistically significant differences in the RNA expression of cartilage matrix molecules, inflammatory cytokines, and matrix metalloproteases were analyzed by the One-Student's T-test in comparison to untreated control cells. For a p-value $<0.05$, the difference was accepted as statistically significant.

Statistically significant changes in the degree of lameness in the case subjects were calculated with an analysis of variances with repeated measurement. For a $\mathrm{p}$-value $<0.05$, the difference was accepted as statistically significant. Improvements in the dogs' vitality were also calculated with a repeated measurement ANOVA. P-values $<0.05$ were accepted as statistically significant. Changes concerning everyday routine or contact pain were calculated with the Wilcoxon signed-rank test in comparison to the baseline situation. For a p-value $<0.05$, the difference was accepted as statistically significant.

Alterations in the biomarkers' plasma content and in the physiological, osteoarthritic-related parameters of the case subjects were statistically validated by sign-tests in comparison with the baseline situation. For completeness of the results, this data is listed in a table format.

\section{Results and Discussion}

\subsection{Mechanism of Action of Specific Collagen Peptides}

A clearly increased RNA expression $(\mathrm{p}<0.05)$ of the main extracellular cartilage matrix molecules (type II collagen, aggrecan, elastin) compared to the control cells was induced (Table 3 ) after the PETAGILE treatment of canine chondrocytes. The positive impact of the specific collagen peptides on cartilage metabolism was also demonstrated by an increased accumulation of new synthesized collagen type II (7.5\%), aggrecan (5.5\%) and elastin $(6.3 \%)$ at the end of the stimulation period of 2 - 3 weeks.

Moreover, the statistically significant $(\mathrm{p}<0.05)$ down regulation of inflamematory cytokines and of degenerative matrix metalloproteases (Table 3 ) indicated that the metabolic processes of the chondrocytes are directly influenced by

Table 3. Gene expression profile in canine chondrocytes by specific collagen peptides supplementation. An increment of the biosynthesis of ECM-molecules is shown in relation to the baseline situation $(+\%)$. ( $\mathrm{n}=46, \mathrm{x}$-fold of control, Student's T-test, $\mathrm{p}<$ 0.05 statistically significant, Coll. Type II = collagen type II, TNF $\alpha=$ tumor necrosis factor $\alpha, \mathrm{IL}=$ interleukin, MMP $=$ matrix metalloprotease, ADAMTS = a disintegrin and metalloprotease with thrombospondin-1-like domains).

\begin{tabular}{|c|c|c|c|c|c|c|c|c|c|}
\hline \multirow[b]{2}{*}{ Gene } & \multicolumn{3}{|c|}{ Extracellular matrix } & \multicolumn{3}{|c|}{ Inflammatory cytokines } & \multicolumn{3}{|c|}{ Degenerative proteases } \\
\hline & $\begin{array}{l}\text { Coll. } \\
\text { type II }\end{array}$ & Aggrecan & Elastin & $\mathrm{TNF} \alpha$ & $\mathrm{IL}-1 \beta$ & IL-6 & MMP-13 & ADAMTS4 & ADAMTS5 \\
\hline $\bar{x} \pm \mathrm{SEM}$ & $\begin{array}{c}1.62 \pm 0.33 \\
(+7.5 \%)\end{array}$ & $\begin{array}{c}3.23 \pm 1.01 \\
(+5.5 \%)\end{array}$ & $\begin{array}{c}13.0 \pm 4.33 \\
(+6.3 \%)\end{array}$ & $0.44 \pm 0.15$ & $0.15 \pm 0.05$ & $0.55 \pm 0.16$ & $0.23 \pm 0.05$ & $0.07 \pm 0.03$ & $0.01 \pm 0.01$ \\
\hline p-value & 0.034 & 0.018 & 0.024 & 0.003 & $<0.001$ & 0.003 & $<0.001$ & $<0.001$ & $<0.001$ \\
\hline
\end{tabular}


the specific collagen peptides.

\subsection{Efficacy of Specific Collagen Peptides in Osteoarthritic Dogs}

In the current investigation, the beneficial effect of PETAGILE on joint cartilage was validated in a small number of osteoarthritic dogs that had previously not reacted to osteoarthritic treatments. The supplementation of $5 \mathrm{~g}$ of PETAGILE per day to the regular diet resulted in a statistically significant $(\mathrm{p}<0.001)$ reduction in lameness compared to the situation at the beginning of the treatment (Figure 1). Only minor symptoms were described by the attending veterinarians after the 12-week treatment period.

The veterinary findings were confirmed by a continuous increase in the vitality of the animals $(\mathrm{p}<0.001)$ as observed by the dogs' owners (Figure 1$)$. The positive influence of the specific collagen peptides was supported by a high effect size level for both assessments $\left(\eta^{2}>0.5\right)$.

Pet owners also reported on improvements in their dogs' daily routines. After 12 weeks of treatment, a statistically significant decreased discomfort in standing up $(\mathrm{p}=0.007$, Figure 2$)$ and a clear reduction in contact pain was reported by the dog owners $(p=0.001$, Figure 3$)$. The beneficial effect of the specific collagen peptides was also demonstrated by the large effect size of $\eta^{2}=0.2125$ for these parameters. In contrast, discomfort at climbing stairs only showed a smaller improvement by trend $\left(\mathrm{p}=0.089, \eta^{2}=0.0296\right)$. This might be due to the less pronounced symptoms at the beginning of treatment among the dogs when climbing stairs.

A more detailed analysis of various blood parameters was performed on three dogs in which the attending veterinarians had observed a statistically significant improvement in the degree of lameness and lameness-related discomfort after 12

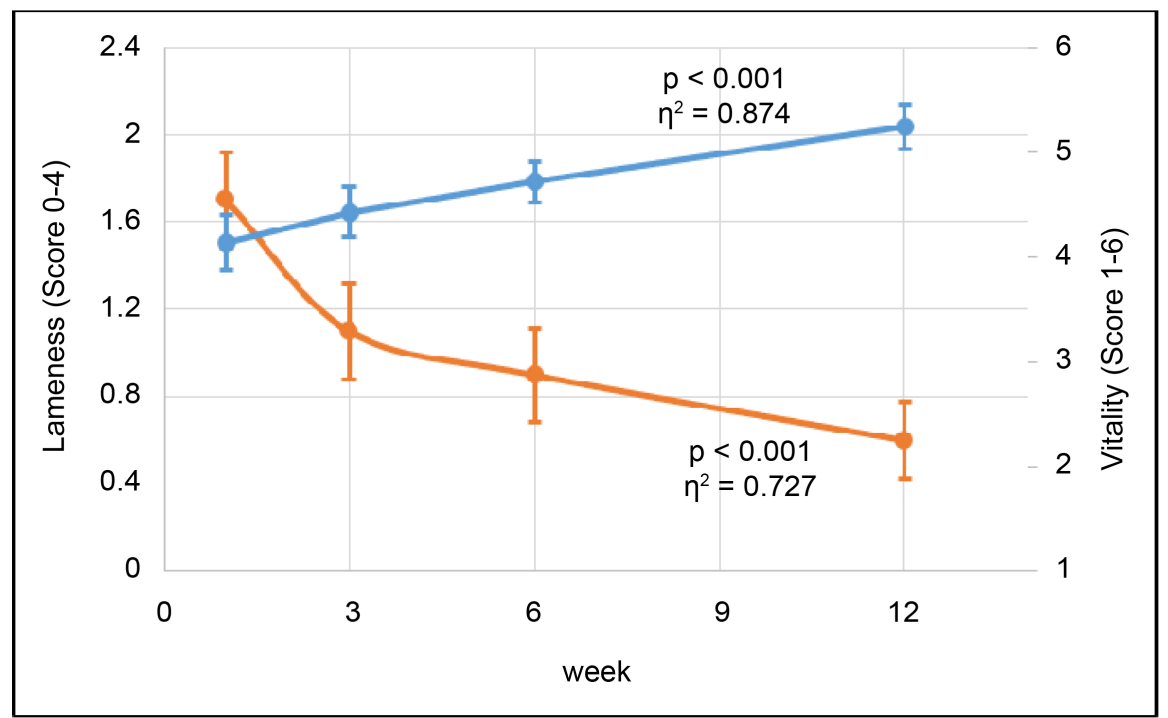

Figure 1. The lameness of the osteoarthritic dogs decreased continuously in the course of the collagen peptide treatment as stated by the attending veterinaries (orange line). During the study period, the pet owners observed an increased vitality in their dogs (blue line, $\bar{x} \pm$ SEM, ANOVA, $\mathrm{p}<0.05$ statistically significant, $\eta^{2}=$ effect size). 


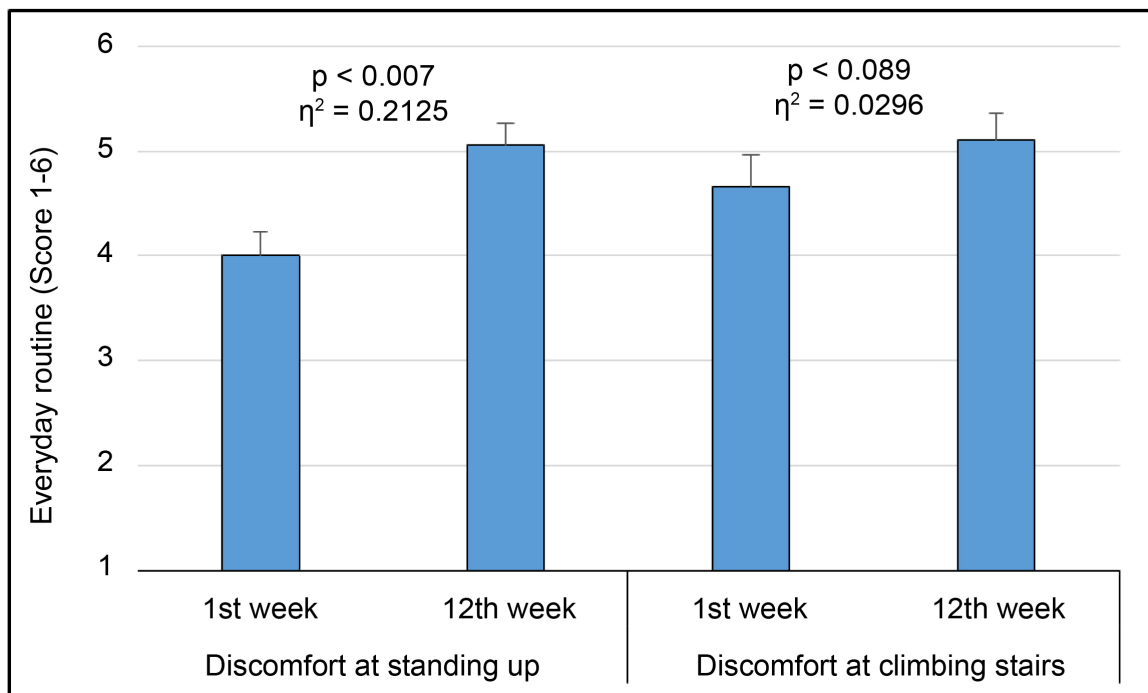

Figure 2. Evaluation of the everyday routine of the osteoarthritic dogs. Comparison of the evaluated parameters "discomfort at standing up" and "discomfort at climbing stairs" at the end of the treatment period ( $12^{\text {th }}$ week) in comparison with the baseline situation $\left(1^{\text {st }}\right.$ week, $\bar{x} \pm$ SEM, Wilcoxon rank-test, $\mathrm{p}<0.05$ statistically significant, $\eta^{2}=$ effect size).

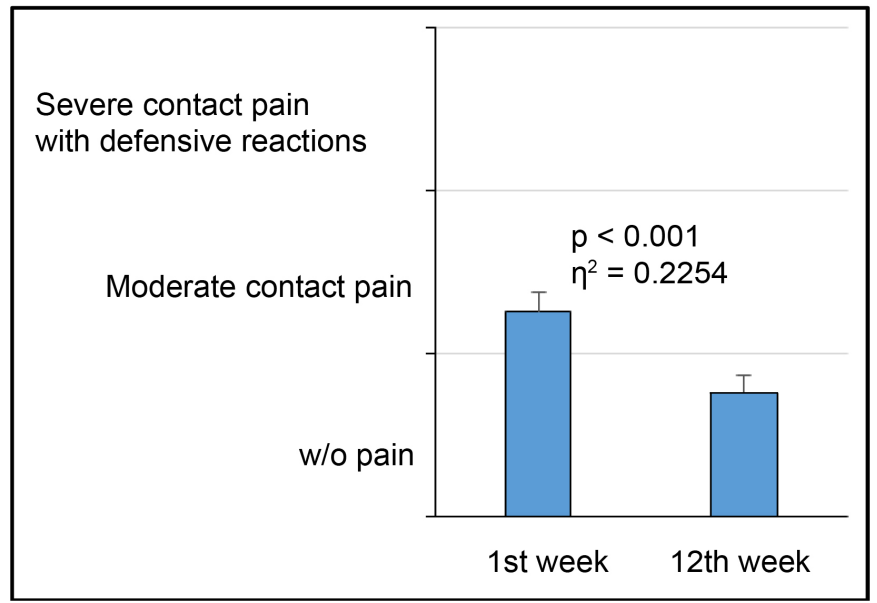

Figure 3. Evaluation of "contact pain" by pet owners at the end of the treatment period $\left(12^{\text {th }}\right.$ week) in comparison with the baseline situation ( $1^{\text {st }}$ week, $\bar{x} \pm$ SEM, Wilcoxon rank-test, $\mathrm{p}<0.05$ statistically significant, $\eta^{2}=$ effect size).

weeks of treatment $(\mathrm{p}=0.006)$. All the dogs were crossbreed, older $(8,9$ and 11 years) and a relieving posture in one or both front limbs was diagnosed during the orthopedic examination. Moreover, the dogs were characterized on a 5-point scale of the body conditioning score (BCS). As osteoarthritis is often associated with overweight [18] [19], the body weight of the animals was also checked. Two female dogs were slightly overweight with $10 \%$ above the ideal body weight, while the one male dog had a normal BCS (Table 4).

The blood-sample analyses revealed a positive impact on the cartilage matrix molecule synthesis after supplementation with the specific collagen peptides (Table 5). The amount of the metabolic biomarkers CP-II, CS846, HA, and 
Table 4. Demographic values of three case subjects and validation of osteoarthritic-related parameters by the attending veterinarians at baseline and end of treatment $\left(12^{\text {th }}\right.$ week, $\mathrm{y}=$ year, $\mathrm{kg}=$ kilogram $)$.

\begin{tabular}{|c|c|c|c|c|c|c|}
\hline Case subject & \multicolumn{2}{|l|}{1} & \multicolumn{2}{|c|}{2} & \multicolumn{2}{|c|}{3} \\
\hline Breed & \multicolumn{2}{|c|}{ Crossbreed } & \multicolumn{2}{|c|}{ Crossbreed } & \multicolumn{2}{|c|}{ Crossbreed } \\
\hline Age & \multicolumn{2}{|c|}{$11 \mathrm{y}$} & \multicolumn{2}{|c|}{$9 y$} & \multicolumn{2}{|c|}{$8 \mathrm{y}$} \\
\hline Gender & \multicolumn{2}{|c|}{ Female } & \multicolumn{2}{|c|}{ Female } & \multicolumn{2}{|c|}{ Male } \\
\hline Weight & \multicolumn{2}{|c|}{$14 \mathrm{~kg}$} & \multicolumn{2}{|c|}{$33 \mathrm{~kg}$} & \multicolumn{2}{|c|}{$37 \mathrm{~kg}$} \\
\hline $\begin{array}{c}\text { Body } \\
\text { Conditioning Score }\end{array}$ & \multicolumn{2}{|c|}{$10 \%$ above ideal body weight } & \multicolumn{2}{|c|}{$10 \%$ above ideal body weight } & \multicolumn{2}{|c|}{ Ideal body weight } \\
\hline $\begin{array}{l}\text { Orthopedic } \\
\text { examination }\end{array}$ & \multicolumn{2}{|c|}{$\begin{array}{l}\text { Relieving posture at } \\
\text { right front limb }\end{array}$} & \multicolumn{2}{|c|}{$\begin{array}{l}\text { Relieving posture at } \\
\text { both front limbs }\end{array}$} & \multicolumn{2}{|c|}{ Relieving posture at both front limbs } \\
\hline Validation & baseline & $12^{\text {th }}$ week & baseline & $12^{\text {th }}$ week & baseline & $12^{\text {th }}$ week \\
\hline Pain at activity & moderate-severe & low & moderate & low & moderate-severe & moderate \\
\hline Joint swelling & low & low & low-moderate & none & low-moderate & low \\
\hline Instability & low & low & low & low & moderate & low \\
\hline Restriction of mobility & low-moderate & low & low-moderate & moderate & moderate & low-moderate \\
\hline Lameness & 3 & 2 & $1-2$ & 1 & 2 & 1 \\
\hline
\end{tabular}

Table 5. Cartilage metabolic biomarkers in routine blood samples of the case at baseline and end of treatment $\left(12^{\text {th }} \mathrm{week}, \mathrm{ng} / \mathrm{ml}\right.$ plasma, $\mathrm{y}=$ year, 우 $=$ female, $\hat{\delta}=$ male, $\Delta=$ difference $12^{\text {th }}$ week to baseline, CP-II $=$ procollagen type II, CS $846=$ chondroitin sulfate $846, \mathrm{HA}=$ hyaluronic acid, COMP = cartilage oligomeric matrix protein, MMP-3 = matrix metalloprotease-3, TIMP-1 = tissue inhibitor of metalloproteases-1).

\begin{tabular}{|c|c|c|c|c|c|c|c|}
\hline Case subject & Biomarker & CP-II & CS846 & HA & COMP & MMP-3 & TIMP-1 \\
\hline \multirow{3}{*}{$11 \mathrm{y}+$} & Baseline & 139.35 & 47.99 & 286.20 & 16.58 & 3.11 & 3.30 \\
\hline & $12^{\text {th }}$ week & 547.79 & 53.11 & 406.09 & 20.80 & 2.57 & 3.57 \\
\hline & $\Delta(\mathrm{ng} / \mathrm{ml})$ & +408.44 & +5.12 & +119.89 & +4.22 & -0.54 & +0.27 \\
\hline \multirow{3}{*}{$9 \mathrm{y}$ 우 } & Baseline & 576.67 & 44.06 & 334.61 & 13.41 & 1.33 & 13.41 \\
\hline & $12^{\text {th }}$ week & 712.28 & 46.54 & 193.09 & 15.37 & 1.26 & 132.57 \\
\hline & $\Delta(\mathrm{ng} / \mathrm{ml})$ & +135.61 & +2.48 & -141.52 & +1.96 & -0.07 & +119.16 \\
\hline \multirow{3}{*}{$8 \mathrm{y}{ }^{\pi}$} & Baseline & 493.95 & 53.59 & 136.53 & 13.26 & 1.44 & not detectable \\
\hline & $12^{\text {th }}$ week & 1326.6 & 59.35 & 413.96 & 15.97 & 1.17 & 9.68 \\
\hline & $\Delta(\mathrm{ng} / \mathrm{ml})$ & +832.65 & +5.76 & +277.43 & +2.71 & -0.27 & - \\
\hline
\end{tabular}

COMP increased after 12 weeks of collagen peptides supplementation compared to the baseline situation. Biomarkers associated with degenerative cartilage processes were also positively influenced by the specific collagen peptides. The MMP-3 plasma content decreased at the end of the treatment whereas the amount of its antagonist, TIMP-1, increased. A statistically significant difference ( $p<0.001$ ) was determined for alterations in all the osteoarthritis-related biomarkers tested in comparison with the baseline situation.

The modified plasma levels of MMP-3 and TIMP-1 in particular confirmed the findings described by Weide [3] for collagen peptide treatment in osteoarthritic dogs.

Our findings suggest that the efficacy of specific collagen peptides for the 
treatment of osteoarthritis is not only based on its anti-degenerative and anti-inflammatory potential, but instead, seems to be primarily a consequence of its positive impact on the metabolism of extracellular cartilage matrix molecules. This could be demonstrated for the first time, to the best of our knowledge, for the same specific collagen peptides on primary canine chondrocytes and under in-vivo conditions. The correlation with the results of the cell-culture experiments and of the treatment success in osteoarthritic dogs clearly demonstrate the effectiveness of the specific collagen peptides, PETAGILE, in the current research.

The stimulation of the chondrocyte matrix metabolism and reduced lameness with a resulting increased vitality in osteoarthritic dogs are accompanied by an appropriate blood plasma profile of biomarkers, which directly corresponded with metabolic processes in cartilage tissue. That biomarkers such as hyaluronic acid (HA) correlate very well with an osteoarthritic disease pattern in dogs was already described by Plickert in 2011 [20].

Our experimental set-up for the treatment of osteoarthritic dogs further indicated that PETAGILE is an optimized mixture of specific collagen peptides for the treatment of pets. In recent trials on osteoarthritic dogs of similar age and body weight, a daily dosage of 10 or $20 \mathrm{~g}$ of collagen peptides were required to achieve a positive impact in osteoarthritis treatment [1] [2] [3]. In our current research, the dosage of specific collagen peptides could be reduced to $5 \mathrm{~g}$ per day to achieve an osteoarthritic treatment success.

The current investigation clearly demonstrated the effectiveness of specific collagen peptides that focus mainly on the regeneration of the extracellular cartilage matrix. Our data suggests that inflammatory and degenerative processes may be reduced after PETAGILE supplementation and, as a consequence, an improvement in cartilage structure could be determined.

\section{Conclusions}

The effectiveness of PETAGILE is clearly demonstrated in primary canine chondrocytes as shown by a statistically significant stimulation of the extracellular cartilage matrix synthesis and the decreased expression of inflammatory cytokines and matrix metalloproteases.

Osteoarthritic dogs benefit from PETAGILE administration, as the decrease in lameness and increased vitality illustrates. The data suggest that specific collagen peptides can improve cartilage extracellular matrix structure, as demonstrated by the positive impact of the cartilage-related plasma biomarkers as well as by the stimulated biosynthesis of matrix molecules in canine chondrocytes.

The beneficial effect of PETAGILE with respect to degenerative processes in cartilage was moreover demonstrated by a decrease in MMP-3 content and by a concurrent increased level of TIMP-1 in the plasma samples of the case subjects.

Although the current results confirm the anti-inflammatory effects and protection against degenerative processes of collagen peptides for the treatment of osteoarthritis in dogs, the stimulation of the cartilage matrix synthesis seems to 
be even more important in the treatment of osteoarthritis, as illustrated by the increased synthesis of collagen type II $(+7.5 \%)$, aggrecan $(+5.5 \%)$, and elastin $(6.3 \%)$ in canine chondrocytes.

The current investigation demonstrated the positive impact of the specific collagen peptides PETAGILE on osteoarthritis in dogs and suggests a possible mode of action.

On the basis of these results, a randomized, double-blind and placebo-controlled clinical study is currently planned to confirm the efficacy of PETAGILE for the treatment of osteoarthritic dogs.

\section{References}

[1] Beynen, A.C., van Geene, H.W., Grim, H.V., Jacobs, P. and van der Vlerk, T. (2010) Oral Administration of Gelatin Hydrolysate Reduces Clinical Signs of Canine Osteoarthritis in a Double-Blind, Placebo-Controlled Trial. American Journal of Animal and Veterinay Sciences, 5,102-106. https://doi.org/10.3844/ajavsp.2010.102.106

[2] Hesse, K.J.F. (2006) Supplementation by Collagen Hydrolysate in Dogs Suffering from Osteoarthritis. Kleintiermedizin, 9, 17-22.

[3] Weide, N. (2004) Der Einsatz von Gelatinehydrolysat bei klinisch-orthopädisch gesunden Hunden und Hunden mit chronischen Erkrankungen des Bewegungsapparats.

[4] Mele, E. (2007) Epidemiologie der Osteoarthritis/Osteoarthrose (OA). Veterinary Focus, 17, 4-10.

[5] Wiseman, M.L., Nolan, A.M., Reid, J. and Scott, E.M. (2001) Preliminary Study on Owner-Reported Behaviour Changes Associated with Chronic Pain in Dogs. Veterinary Record, 149, 423-424. https://doi.org/10.1136/vr.149.14.423

[6] Comblain, F., Serisier, S., Barthelemy, N., Balligand, M. and Henrotin, Y. (2016) Review of Dietary Supplements for the Management of Osteoarthritis in Dogs in Studies from 2004 to 2014. Journal of Veterinary Pharmacology and Therapeutics, 39, 1-15. https://doi.org/10.1111/jvp.12251

[7] Johnston, S.A. (1997) Osteoarthritis: Joint Anatomy, Physiology, and Pathobiology. Veterinary Clinics of North America: Small Animal Practice, 27, 699-723. https://doi.org/10.1016/S0195-5616(97)50076-3

[8] Belshaw, Z., Asher, L. and Dean, R.S. (2016) The Attitudes of Owners and Veterinary Professionals in the United Kingdom to the Risk of Adverse Events Associated with Using Non-Steroidal Anti-Inflammatory Drugs (NSAIDs) to Treat Dogs with Osteoarthritis. Preventive Veterinary Medicine, 131,121-126. https://doi.org/10.1016/j.prevetmed.2016.07.017

[9] Moreau, M., Troncy, E., Del Castillo, J.R.E., Bedard, C., Gauvin, D. and Lussier, B. (2012) Effects of Feeding a High Omega-3 Fatty Acids Diet in Dogs with Naturally Occurring Osteoarthritis. Journal of Animal Physiology and Animal Nutrition, 97, 830-837. https://doi.org/10.1111/j.1439-0396.2012.01325.x

[10] Roush, J.K., Cross, A.R., Renberg, W.C., Dodd, C.E., Sixby, K.A., Fritsch, D.A., Allen, T.A., Jewell, D.E., Richardson, D.C., Leventhal, P.S. and Hahn, K.A. (2010) Evaluation of the Effects of Dietary Supplementation with Fish Oil Omega-3 Fatty Acids on Weight Bearing in Dogs with Osteoarthritis. Journal of the American Veterinary Medical Association, 236, 67-73. https://doi.org/10.2460/javma.236.1.67

[11] Roush, J.K., Dodd, C.E., Fritsch, D.A., Allen, T.A., Jewell, D.E., Schoenherr, W.D., Richardson, D.C., Leventhal, P.S. and Hahn, K.A. (2010) Multicenter Veterinary Practice Assessment of the Effects of Omega-3 Fatty Acids on Osteoarthritis in 
Dogs. Journal of the American Veterinary Medical Association, 236 59-66. https://doi.org/10.2460/javma.236.1.59

[12] Schneider, L. (2013) Nutraceuticals and Their Use in Veterinary Practices. The New Zealand Veterinary Nurse, 8-11.

[13] Vandeweerd, J.M., Coisnon, C., Clegg, P., Cambier, C., Pierson, A., Hontoir, F., Saegerman, C., Gustin, P. and Buczinski, S. (2012) Systematic Review of Efficacy of Nutraceuticals to Alleviate Clinical Signs of Osteoarthritis. Journal of Veterinary Internal Medicine, 26, 448-456. https://doi.org/10.1111/j.1939-1676.2012.00901.x

[14] Bach, F.C., Willems, N., Penning, L.C., Ito, K., Meij, B.P. and Tryfonidou, M.A. (2014) Potential Regenerative Treatment Strategies for Intervertebral Disc Degeneration in Dogs. BMC Veterinary Research, 10, 3.

https://doi.org/10.1186/1746-6148-10-3

[15] Buckwalter, J.A. and Mankin, H.J. (1998) Articular Cartilage: Degeneration and Osteoarthritis, Repair, Regeneration, and Transplantation. Instructional Course Lectures, 47, 487-504.

[16] McAlindon, T.E., Nuite, M., Krishnan, N., Ruthazer, R., Price, L.L., Burstein, D., Griffith, J. and Flechsenhar, K. (2011) Change in Knee Osteoarthritis Cartilage Detected by Delayed Gadolinium Enhanced Magnetic Resonance Imaging Following Treatment with Collagen Hydrolysate: A Pilot Randomized Controlled Trial. Osteoarthritis and Cartilage, 19, 399-405. https://doi.org/10.1016/j.joca.2011.01.001

[17] (2011) Guide for the Care and Use of Laboratory Animals. 8 Edition, The National Academies Press.

[18] Baldwin, K., Bartges, J., Buffington, T., Freeman, L.M., Grabow, M., Legred, J. and Ostwald Jr., D. (2010) AAHA Nutritional Assessment Guidelines for Dogs and Cats. Journal of the American Animal Hospital Association, 46, 285-296. https://doi.org/10.5326/0460285

[19] Marshall, W., Bockstahler, B., Hulse, D. and Carmichael, S. (2009) A Review of Osteoarthritis and Obesity: Current Understanding of the Relationship and Benefit of Obesity Treatment and Prevention in the Dog. Veterinary and Comparative Orthopaedics and Traumatology, 22, 339-345. https://doi.org/10.3415/vcot-08-08-0069

[20] Plickert, H.D. (2011) Biomarker der Osteoarthritis des Hundes: Untersuchung von Myeloperoxidase, C-reaktivem Protein, Hyaluronsäure und $\mathrm{C} 2 \mathrm{C}$ in Synovia und Serum. 1-215.

\section{Submit or recommend next manuscript to SCIRP and we will provide best service for you:}

Accepting pre-submission inquiries through Email, Facebook, LinkedIn, Twitter, etc. A wide selection of journals (inclusive of 9 subjects, more than 200 journals)

Providing 24-hour high-quality service

User-friendly online submission system

Fair and swift peer-review system

Efficient typesetting and proofreading procedure

Display of the result of downloads and visits, as well as the number of cited articles

Maximum dissemination of your research work

Submit your manuscript at: http://papersubmission.scirp.org/

Or contact ojas@scirp.org 